\title{
ANÁLISE DA FRAGMENTAÇÃO DA PAISAGEM DO MUNICÍPIO DE NOVA MARILÂNDIA-MT, BRASIL
}

\author{
Alexander Webber Perlandim Ramos \\ Universidade Federal de Minas Gerais, Belo Horizonte, MG, Brasil \\ webber.unemat@gmail.com \\ Edinéia Aparecida dos Santos Galvanin \\ Universidade Estadual Paulista, Ourinhos, SP, Brasil \\ edineia.galvanin@unesp.br \\ Sandra Mara Alves da Silva Neves \\ Universidade do Estado de Mato Grosso, Cáceres, MT, Brasil \\ ssneves@unemat.com
}

\begin{abstract}
RESUMO
Este trabalho tem como objetivo analisar o estado de fragmentação da paisagem do município de Nova Marilândia - Mato Grosso, visando a geração de informações que subsidiem a proposição de estratégias de planejamento para conservação e restauração da funcionalidade da paisagem. Os mapas de cobertura vegetal e usos da terra foram gerados a partir de imagens dos satélites Landsat 5, dos anos de 1998 e 2008, e Landsat 8, de 2018. Foram realizados os processos de georreferenciamento, recorte e classificação. A aplicação dos cálculos estatísticos relativos à estrutura da paisagem foi operacionalizada no programa Fragstats. No período de análise, houve alta antropização na paisagem do município, implicando na redução das áreas das classes de Vegetação Natural Florestal $(10,49 \%)$ e Formação Savânica $(20,95 \%)$, e um crescimento das áreas de Pastagem $(36,00 \%)$ e Agricultura $(103,74 \%)$, resultando no aumento da fragmentação da paisagem municipal. Concluiu-se que ocorreu um aumento da complexidade das formas e nas distâncias entre os fragmentos de vegetação nativa e a redução da conectividade funcional, ocasionada pelo crescimento expressivo das áreas de Agricultura e Pastagem, que se constituem como as principais bases econômicas do município.
\end{abstract}

Palavras-chave: Agricultura. Desmatamento. Geotecnologias. Métricas. Pastagem.

\section{ANALYSIS OF LANDSCAPE FRAGMENTATION OF THE MUNICIPALITY OF NOVA MARILÂNDIA-MT, BRAZIL}

\section{ABSTRACT}

This work aims to analyze the state of fragmentation of the landscape of the municipality of Nova Marilândia - Mato Grosso, aiming at generating information that supports the proposition of planning strategies for the conservation and restoration of landscape functionality. Maps of vegetation cover and land uses were generated from images of Landsat 5 satellites, from 1998 and 2008, and Landsat 8, 2018. Georeferencing, clipping and classification processes were performed. The application of statistical calculations relating to the structure of the landscape was operationalized in the Fragstats programme. In the analysis period, there was high anthroporization in the landscape of the municipality, implying the reduction of the areas of the classes of Natural Forest Vegetation (10.49\%) and Savannah Formation (20.95\%), and a growth in Pasture areas (36.00\%) Agriculture (103.74\%), resulting in increased fragmentation of the municipal landscape. It was concluded that there was an increase in the complexity of the forms and distances between the fragments of native vegetation and the reduction of functional connectivity, caused by the expressive growth of the areas of Agriculture and Pasture, which constitute the the main economic bases of the municipality.
\end{abstract}

Keywords: Agriculture. Deforestation. Geotechnologies. Metrics. Pasture.

\section{INTRODUÇÃO}

Compreendida como resultado de uma combinação dinâmica, a paisagem é a interrelação dos elementos físicos, biológicos e antrópicos, que, reagindo uns sobre os outros, fazem da paisagem um conjunto único e indissociável em constante evolução (BERTRAND, 1968).

As pressões antrópicas geradas sobre os componentes naturais das paisagens, em especial a vegetação, têm-se tornado um grande entrave para a conservação da biodiversidade, ocasionando problemas ambientais como a fragmentação dos ecossistemas, resultando, de acordo com Szmuchrowski e Martins (2001, p. 676), em:

"[...] mudanças na estrutura da comunidade como a quebra na cadeia alimentar, perda de indivíduos reprodutivos de populações vegetais e animais, modificação e/ou eliminação de relações ecológicas com outras espécies como polinizadores, efeitos indiretos que são importantes sobre as espécies que restam nestes ambientes através de mudanças no microclima, entre outros efeitos de ordem física e biológica."

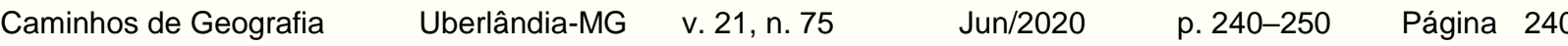


Diante dessas problemáticas, diversos índices/métricas foram elaborados para identificar e avaliar os padrões de arranjos espaciais da paisagem, possibilitando a quantificação e a tipificação de suas características nas análises dos ambientes (MCGARIGAL e MARKS, 1995; FORERO-MEDINA e VIEIRA, 2007; SU et al., 2012). De acordo com Silva e Lima (2019), a utilização desses índices dá aporte ao processo de identificação dos padrões e fluxos estruturais da paisagem, o que é essencial para a compreensão das relações ecológicas nela contida.

Para tanto, é fundamental a aplicação das geotecnologias no levantamento de dados e elaboração de análises, permitindo a geração de informações relevantes na avaliação das condições da vegetação, visto que inúmeros dados podem ser obtidos por meio do processamento de imagens de sensoriamento remoto em Sistema de Informação Geográfica (BATISTELLA et al., 2011). Tais dados possibilitam o cálculo de índices capazes de descrever o nível de fragmentação dos ambientes, possibilitando a realização de estudos da paisagem associados à conservação ambiental e da biodiversidade (SOUZA et al., 2014).

Face ao exposto, no presente trabalho, o objetivo é analisar o estado de fragmentação da paisagem do município de Nova Marilândia, no Mato Grosso, visando a geração de informações que subsidiem a proposição de estratégias de planejamento para conservação e restauração da funcionalidade da paisagem.

\section{MATERIAIS E MÉTODOS}

\section{Área de estudo}

O município de Nova Marilândia compreende a área territorial de 1.934,8 km² (BRASIL, 2018) e integra, segundo Mato Grosso (2017) a região Oeste de planejamento do estado de Mato Grosso (Figura 1). A população municipal é de 2.951 habitantes, com Índice de Desenvolvimento Humano (IDH) de 0,704 (BRASIL, 2018).

Figura 1 - Município de Nova Marilândia, nos contextos brasileiro e mato-grossense.
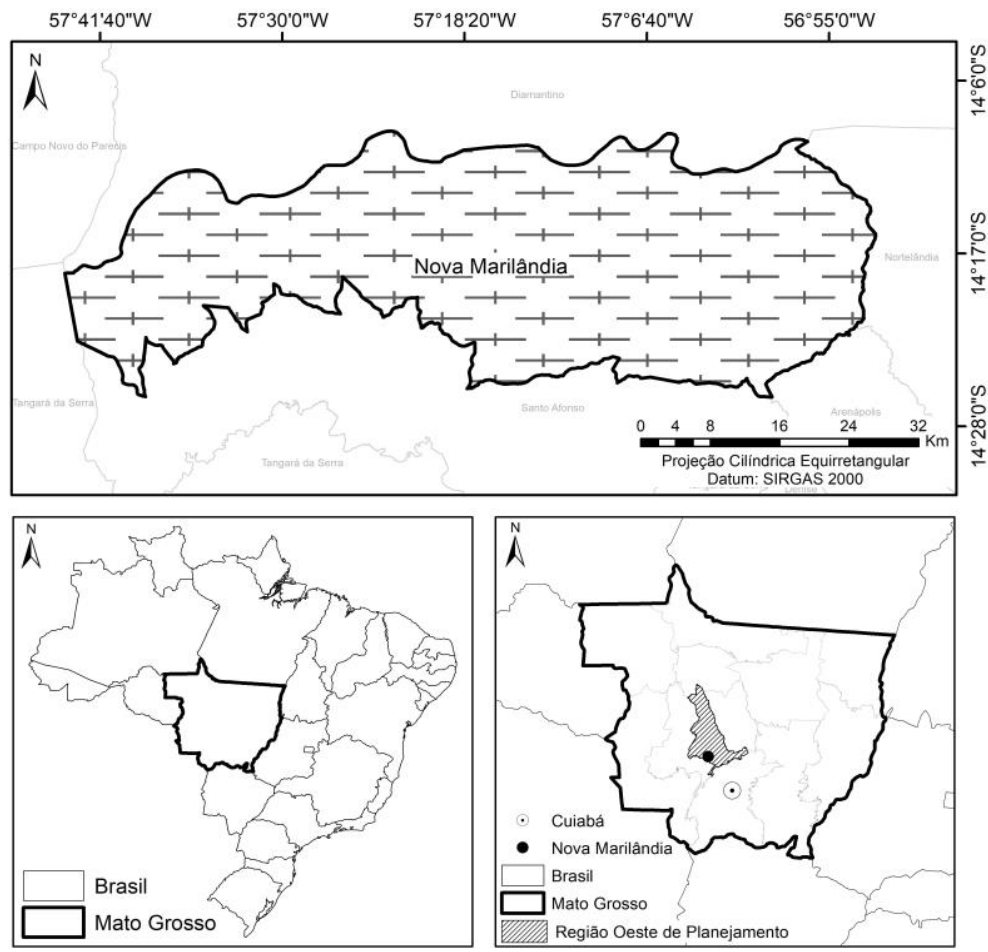

Elaboração: os autores.

A extensão da municipalidade de Nova Marilândia está distribuída em uma área de transição dos biomas Cerrado e Amazônia. O clima na região é o tropical úmido megatérmico, com temperaturas médias anuais acima de $25^{\circ} \mathrm{C}$ e precipitação total que varia entre 1400 e $1600 \mathrm{~mm}$. Suas principais características são duas estações bem definidas, seca e chuvosa (TARIFA, 2011).

No município, ocorrem os domínios morfológicos bacias e coberturas sedimentares da Formação Planalto e Chapada dos Parecis (IBGE, 2009), com a predominância dos solos Latossolo Vermelho-Amarelo, Latossolo Vermelho, Argissolo Vermelho-Amarelo, Neossolos Quartzarênicos e Neossolos Litólicos (MATO GROSSO, 2018). O relevo no município é constituído majoritariamente por áreas de relevo plano e suave ondulado. 


\section{Procedimentos metodológicos}

Para a geração dos mapas de cobertura vegetal e usos da terra, foram obtidas, no sítio do Serviço Geológico Americano (USGS, 2018), imagens referentes à órbita 227, ponto 70, do satélite Landsat 5 (bandas 3, 4 e 5), sensor Thematic Mapper (TM), dos anos de 1998 e 2008, e do satélite Landsat 8 (bandas 4, 5 e 6), sensor Operational Land Imager (OLI), de 2018, ambos com resolução espacial de 30 metros. Para as imagens do satélite Landsat 5 , foi realizado o processo de georreferenciamento, que consiste na correção das distorções geométricas, minimizando e/ou eliminando o erro de posicionamento remanescente (OLIVEIRA et al., 2018).

Para realizar a operação de georreferenciamento, foram aplicadas funções polinomiais no espaço bidimensional a fim de relacionar as coordenadas das imagens às suas coordenadas homólogas de referência. Pontos de controle foram distribuídos sobre a imagem para modelar efeitos como a translação, a rotação, mudança de escala, os quais correspondem a erros de posicionamento (SANTOS, 2009). Dessa forma, a partir da relação entre os pontos na imagem a ser corrigida e os pontos na projeção cartográfica, pode-se estabelecer parâmetros para a realização de transformações geométricas, corrigindo as distorções existentes na imagem (OLIVEIRA et al., 2018).

Posteriormente, foram realizados os processos de recorte, utilizando o arquivo vetorial do limite político administrativo do município de estudo como máscara, obtido no sítio da Secretaria de Estado de Planejamento e Coordenação Geral do Estado do Mato Grosso - SEPLAN (MATO GROSSO, 2012), e segmentação, em que foi empregado o método de crescimento de região, cujos valores de limiar de similaridade e de área definidos foi de 15 para as imagens Landsat 5, e 30 para as Landsat 8 . A dissimilitude destes valores foi dada de maneira empírica no processo de segmentação, considerando a diferença de resolução radiométrica entre os satélites Landsat 5 e 8, que é de 8 e 16 bits, respectivamente. $\mathrm{Na}$ classificação supervisionada, foi utilizado o algoritmo Bhattacharya, em que cada classe descrita é associada estatisticamente às regiões definidas nos parâmetros de segmentação através das médias das matrizes de covariância, utilizando-se o critério de distância mínima com limiar de aceitação de 99,99\% (XAUD e EPIPHANIO, 2014).

Foram definidas cinco classes de cobertura vegetal e uso da terra com base no Manual Técnico de Uso da Terra (IBGE, 2013), sendo elas: Agricultura (terras utilizadas para a produção de alimentos, fibras e commodities do agronegócio, incluindo todas as terras cultivadas, caracterizadas pelo delineamento de áreas cultivadas ou em descanso); Formação Savânica (composta por vegetação de campos nativos abertos e vegetação arbórea espaçada e pouco densa, com árvores de pequeno porte); Pastagem (área destinada ao pastoreio do gado formada por gramíneas nativas da região e/ou gramíneas exóticas); Usos Antrópicos (manchas urbanas, sedes rurais e estradas); e Vegetação Natural Florestal (formações arbóreas densas ou abertas com diferentes graus de continuidade).

Para avaliação das transições das diferentes classes de cobertura vegetal e uso da terra, foi aplicado o Diagrama de Sankey, que visa expressar, através de linhas, a proporção e dinâmica de fluxos, seguindo a logicidade de que linhas mais espessas representam maiores deslocamentos de matéria/massa, enquanto que linhas mais finas simbolizam menores volumes (SCHIMIDT, 2008). Para tanto, é realizada uma tabulação cruzada das matrizes de mapeamento que visa mesurar as extensões das classes, a imutabilidade e as transições (ganho/perda) durante os intervalos analisados (CUBA, 2015).

Para a realização dos cálculos estatísticos relativos à paisagem, foi executada a conversão das imagens classificadas do formato Taglmage File Format (TIFF) para o formato Gridded Binary (GRIB). Posteriormente, foram aplicadas as seguintes métricas descritas na Tabela 1, a seguir, utilizando 0 programa Fragstats, versão 4.2.1 (MCGARIGAL e MARKS, 1995).

Tabela 1 - Métricas da paisagem aplicadas ao município de Nova Marilândia-MT.

\begin{tabular}{|c|c|}
\hline Métrica & Descrição \\
\hline $\mathrm{CA}$ & Área total $\left(\mathrm{km}^{2}\right)$ de todos os fragmentos por classe. \\
\hline COHESION & $\begin{array}{l}\text { Soma da conectividade física entre cada fragmento da } \\
\text { mesma classe }\end{array}$ \\
\hline ENN_MN & $\begin{array}{l}\text { Média da somatória de todas as distâncias entre cada } \\
\text { fragmento e o vizinho mais próximo da mesma classe, } \\
\text { dividido pelo número de fragmentos da classe. }\end{array}$ \\
\hline NP & Número de fragmentos existente por classe na paisagem. \\
\hline SHAPE_MN & $\begin{array}{l}\text { Soma do perímetro de cada fragmento dividido pela raiz } \\
\text { quadrada da área, e ajustada para o padrão circular (para } \\
\text { polígonos), dividido pelo número de fragmentos da classe. }\end{array}$ \\
\hline
\end{tabular}




\section{RESULTADOS E DISCUSSÕES}

Durante duas décadas ocorreram intensas mudanças na paisagem do município de Nova Marilândia (Figura 2).

Figura 2 - Mapa de Uso e Cobertura da Terra do município de Nova Mariândia-MT, nos anos de 1998, 2008 e 2018.

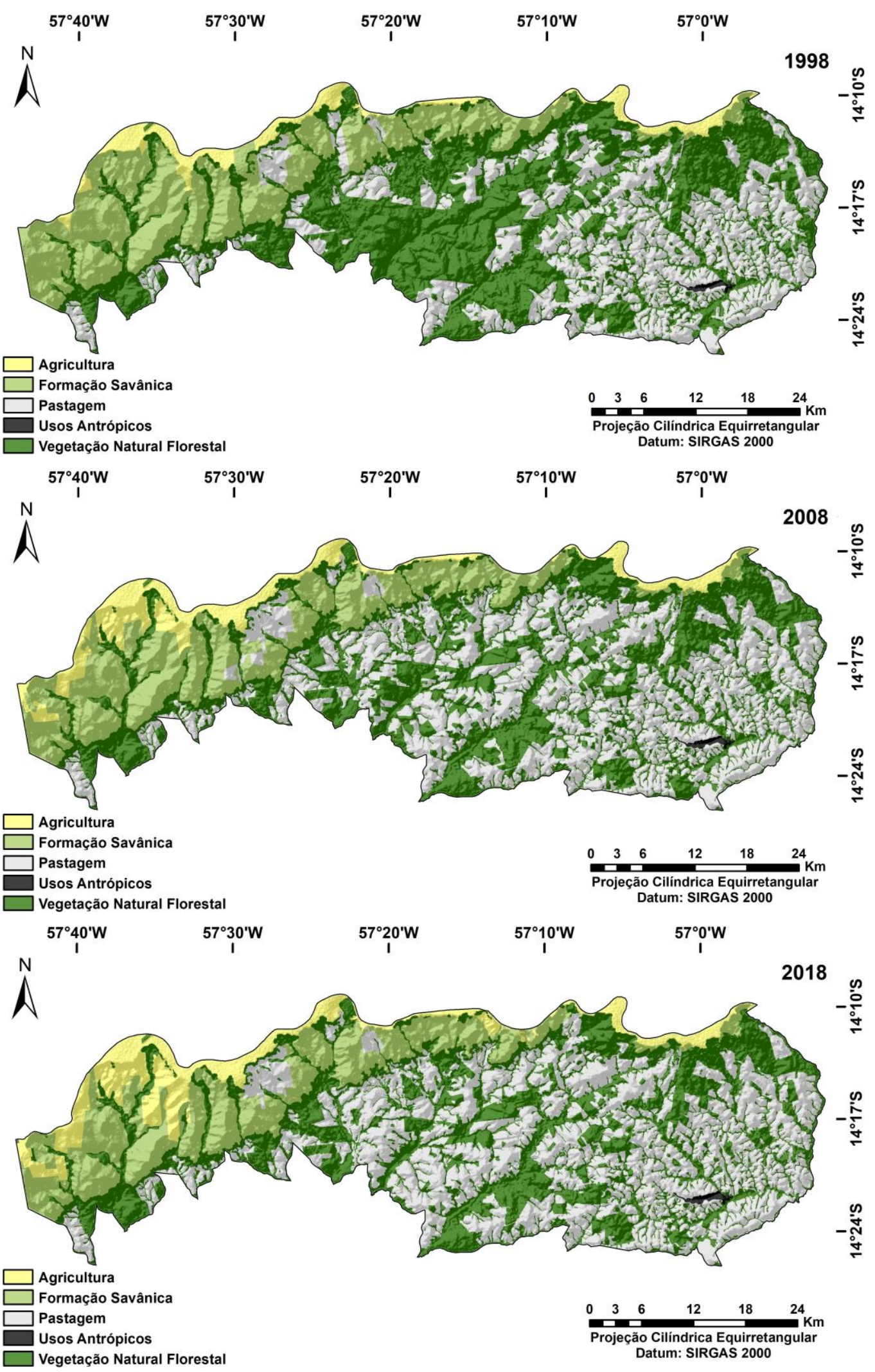

Elaboração: os autores. 
A classe Vegetação Natural Florestal, que representava 46,01\% de toda a extensão territorial, apresentou um declínio de 10,49\% de 1998 para 2018 (Tabela 2, Figura 3), fato que se deu pela remoção vegetal, principalmente para abertura de novas áreas de Pastagem. Pessoa et al. (2013) explicam que a substituição da vegetação nativa para criação de gado e desenvolvimento da agricultura têm provocando, nos últimos anos, intensos desmatamentos em todo país. Em Mato Grosso, esse processo está ligado à expansão das áreas de cultivos agrícolas e, principalmente, da bovinocultura de alto retorno econômico.

Tabela 2 - Índice de Área - CA ( $\left.\mathrm{km}^{2}\right)$ da paisagem do município de Nova Marilândia-MT, nos anos de 1998, 2008 e 2018.

\begin{tabular}{lrrr}
\hline \multicolumn{1}{c}{ Classe } & \multicolumn{1}{c}{$\mathbf{1 9 9 8}$} & \multicolumn{1}{l}{$\mathbf{2 0 0 8}$} & $\mathbf{2 0 1 8}$ \\
\hline Agricultura & 77,39 & 127,26 & 157,68 \\
Formação Savânica & 394,04 & 336,64 & 311,46 \\
Pastagem & 569,27 & 741,41 & 774,22 \\
Usos Antrópicos & 3,77 & 4,08 & 4,21 \\
Vegetação Natural Florestal & 890,34 & 725,42 & 687,23 \\
\hline Área Total & $1.934,81$ & $1.934,81$ & $1.934,81$ \\
\hline
\end{tabular}

Organização: os autores.

Figura 3 - Dinâmica $\left(\mathrm{km}^{2}\right)$ da paisagem do município de Nova Marilândia-MT, nos anos de 1998, 2008 e 2018.

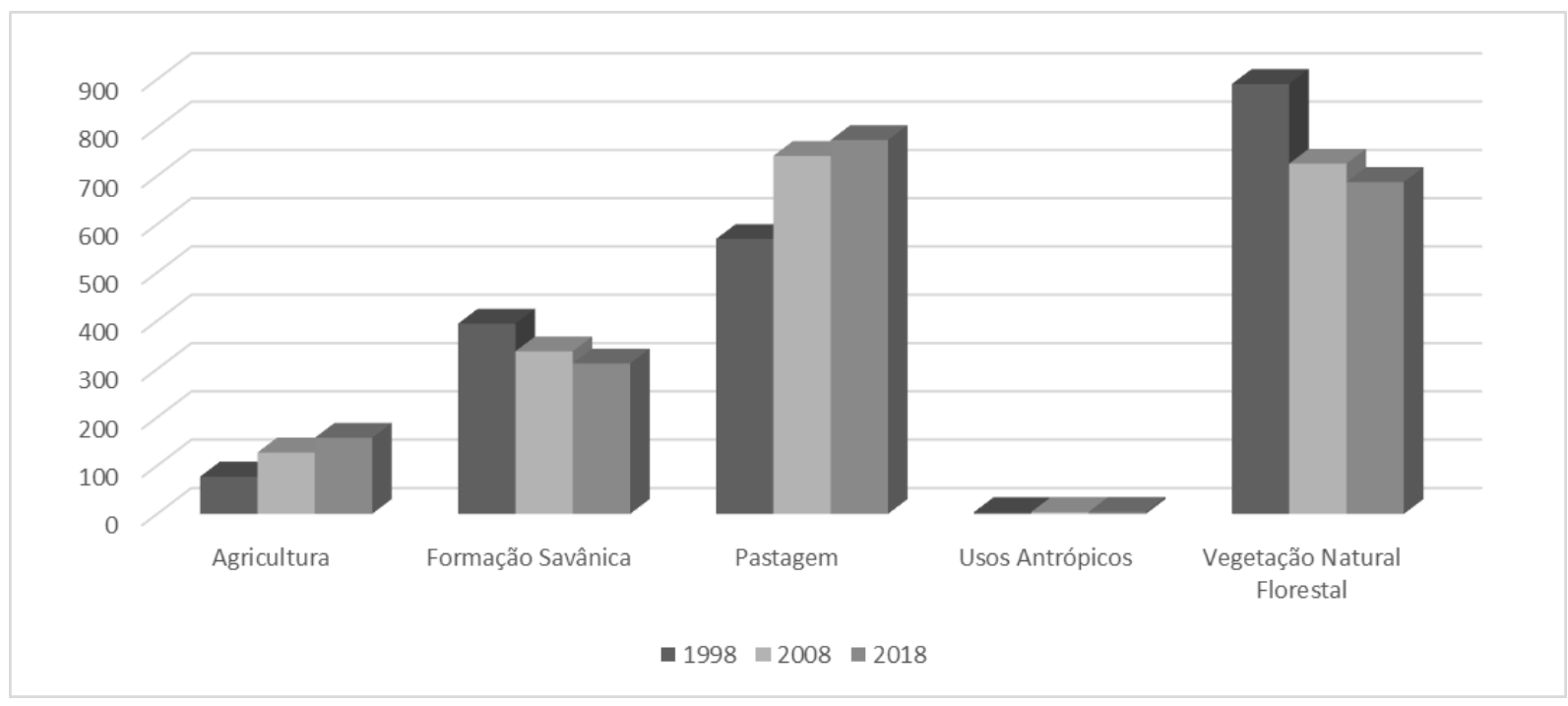

Elaboração: os autores.

As áreas de Pastagem foram as que apresentaram maior crescimento $\left(204,95 \mathrm{~km}^{2}\right)$ durante o período analisado, tendo ocorrido uma inversão entre a classe Vegetação Natural Florestal e Pastagem entre 2008 e 2018 (Figura 4), mostrando a consolidação da ocupação dessa classe no território da municipalidade. Esse resultado corrobora com os dados de Campos e Bacha (2016) entre os anos de 1995 e 2006, em que se verificou em Mato Grosso, uma forte expansão do rebanho bovino. Segundo os autores, o número de bovinos por hectare de pastagem aumentou de 0,67 para 0,94. Em específico no município de Nova Marilândia, os dados do Censo Agropecuário (IBGE, 2017) apontam um aumento de 61.868 cabeças de gado, no ano de 2006, para 64.801, no ano de 2017. 
Figura 4 - Diagrama de Sankey com valores de CA aplicado para os anos de 1998, 2008 e 2018 no município de Nova Marilândia-MT.

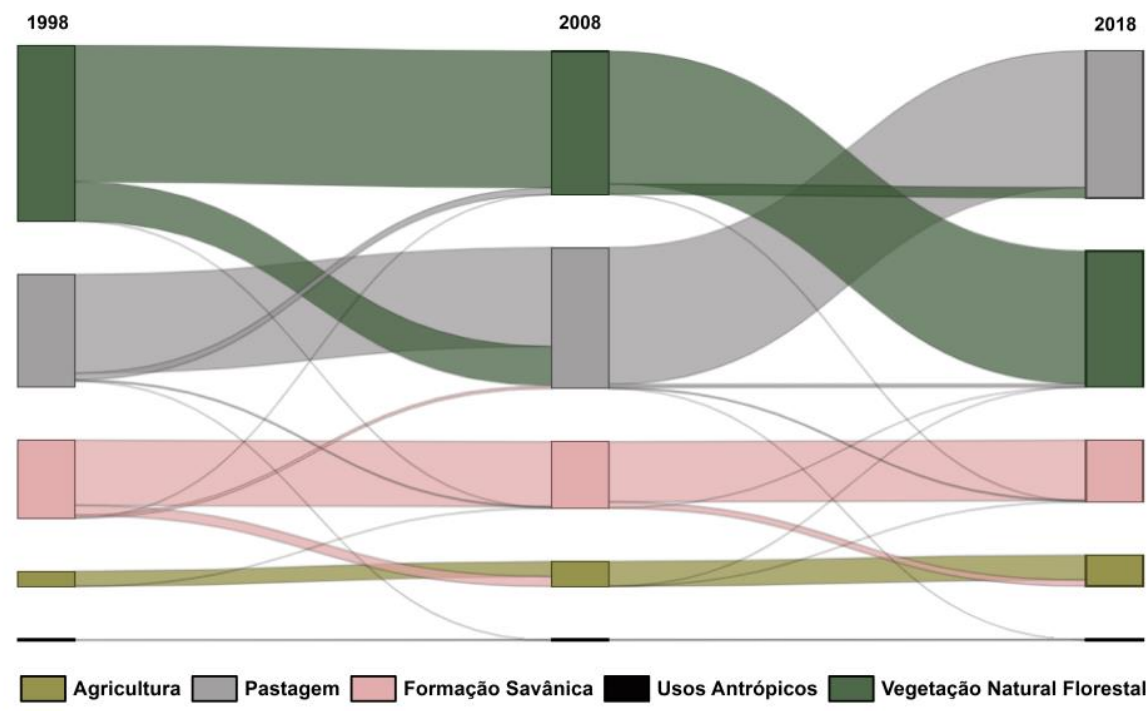

As linhas representam os fluxos de origem e transição das diferentes classes no período analisado por proporção de área. Elaboração: os autores.

As áreas de Formação Savânicas que anteriormente correspondiam a 20,37\% passaram a ocupar $16,10 \%$, enquanto a Agricultura foi de $4,00 \%$ para $8,15 \%$, um aumento de $103,74 \%$. A conversão de áreas de Formação Savânica em Pastagem e, principalmente, em Agricultura pode estar associado ao "boom das commodities", em meados de 2004, e às políticas de incentivos fiscais oferecidos pelo governo federal ao agronegócio, favorecendo a expansão agropecuária, em especial, em Mato Grosso, maior exportador do setor (PAULA e PIRES, 2017).

Os Usos Antrópicos mantiveram um aumento constante de 0,19\%, chegando a 0,22\% de representação de área do município no ano de 2018. Como consequência da supressão das áreas de florestas nativas, têm-se o aumento da fragmentação de habitats que pode ocasionar a diminuição no número de espécies de fauna e flora (FAHRIG et al., 2019).

O número de fragmentos (NP) na área de pesquisa apresentou aumento de $28,53 \%$, ao longo do período analisado. Tais valores foram resultantes, principalmente, da redução das áreas de Vegetação Natural Florestal, que apresentavam um NP de 315, em 1998, que passou para 406, em 2018. A classe Formação Savânica seguiu a mesma tendência, tendo uma elevação do NP de 10 para 16. As classes Agricultura e Pastagem também tiveram aumento no número de fragmentos de 11 para 15 e de 52 para 62 , respectivamente (Figura 5).

Figura 5 - Número de fragmentos por classe (NP) no município de Nova Marilândia-MT, nos anos de 1998, 2008 e 2018.

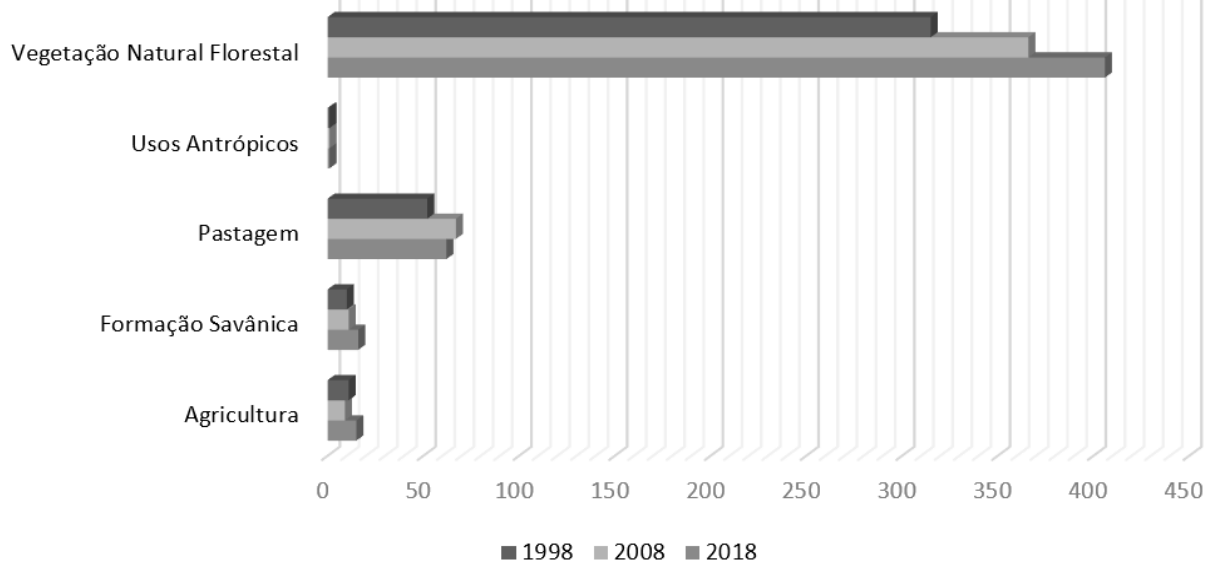

Elaboração: os autores. 
Assim sendo, pode-se afirmar que, durante os anos estudados as formações vegetais nativas foram suprimidas de maneira que ocasionasse a fragmentação destas e o aumento das demais classes que estavam sendo implantadas (Agricultura e Pastagem), fazendo com que o NP dessas classes também fossem elevados e consequentemente o CA.

Os resultados da análise da fragmentação da paisagem apontaram que a conectividade física (COHESION) permanece alta entre os elementos restantes nas classes Vegetação Natural Florestal e Formação Savânica para o ano 2018 (Tabela 3).

Tabela 3 - Percentuais de Conectividade (COHESION) da paisagem do município de Nova Marilândia-MT, nos anos de 1998,2008 e 2018.

\begin{tabular}{lccc}
\hline \multicolumn{1}{c}{ Classe } & $\mathbf{1 9 9 8}$ & $\mathbf{2 0 0 8}$ & $\mathbf{2 0 1 8}$ \\
\hline Agricultura & 96,80 & 98,00 & 98,09 \\
Formação Savânica & 98,73 & 98,59 & 98,43 \\
Pastagem & 98,87 & 98,94 & 99,05 \\
Usos Antrópicos & 93,64 & 93,92 & 94,03 \\
Vegetação Natural Florestal & 99,51 & 99,64 & 99,54 \\
\hline \multicolumn{4}{c}{ Organização: os autores. }
\end{tabular}

A mesma tendência é apresentada pelas classes Agricultura e Pastagem, mostrando que, apesar da paisagem apresentar fragmentação relativamente alta, os fragmentos existentes estão ligados por estruturas físicas. Isso, segundo Metzger et al. (2017), é considerado favorável à conservação desses remanescentes e para aumento da taxa de migração de espécies nas classes que possuem tal função (SOUZA et al., 2014).

De forma geral, a conectividade física (COHESION) na municipalidade apresentou um acréscimo no período estudado, principalmente das classes de uso antrópico. No entanto, cabe ressaltar que tais dados expressaram que há um aumento na conectividade física entre as classes, mas um possível declínio na conectividade funcional, pois as classes mais afetadas são as que abrigam a maior diversidade de espécies florísticas e faunísticas. Isso porque o processo de supressão se deu nas áreas de vegetação natural para desenvolvimento das atividades antrópicas, agrupando as novas áreas abertas a outras existentes, aumentando, assim, a conectividade das áreas antropizadas.

A classe Formação Savânica apresentou redução da distância média dos fragmentos (ENN_MN), de 8,54 $\mathrm{m}$ para $6,47 \mathrm{~m}$, ao longo das duas décadas analisadas, enquanto que, na classe Vegetação Natural Florestal, houve aumento das distâncias dos fragmentos de 3,17 m para 3,24 m, no mesmo período. No caso da classe Formação Savânica, seguiu-se uma tendência oposta da geralmente apresentada por vegetação nativa, como manifestada pela Vegetação Natural Florestal, que é de aumento na distância média dos fragmentos, resultante da supressão florestal para desenvolvimento de atividade antrópica.

Contudo, os dois resultados possuem a mesma causa explicativa que é a citada supressão. No caso das áreas de Savana, trata-se da extinção de fragmentos isolados ao longo do tempo, criando um agrupamento da classe e por resultado uma queda na distância de áreas. E no caso da Vegetação Natural Florestal, o processo foi o mesmo, porém, a abertura de áreas se deu nos centros das classes, aumentando a distâncias médias dos fragmentos de vegetação nativa. Assim, pode-se afirmar que os fragmentos estão relativamente próximos uns dos outros, uma vez que, as distâncias médias entre fragmentos menores que $60 \mathrm{~m}$ são classificadas como baixo grau de isolamento, portanto, favoráveis ao deslocamento de algumas espécies (RIBEIRO et al., 2009; SOUZA et al., 2014).

Diante desse contexto, Metzger (2006) discorre que, ainda que a proximidade entre os fragmentos seja um importante fator para os processos ecológicos, o processo de fragmentação e o valor crescente desse índice tendem a impactar de maneira mais negativa nos fragmentos mais isolados. Desse modo, estes devem ser avaliados quanto à sua importância no contexto ecológico para a manutenção ecossistêmica (NEVES et al., 2014).

Para o índice de forma (SHAPE_MN), foi encontrado o valor de 2,04 para a Formação Savânica e 1,41 para a Vegetação Natural Florestal (Tabela 4), o que demonstra uma paisagem com formas complexas e irregulares (MCGARIGAL e MARKS, 1995). De acordo com Abdalla e Cruz (2015), esses valores indicam que os fragmentos florestais apresentam formas mais arredondadas, favorecendo a proteção do seu interior dos efeitos de borda.

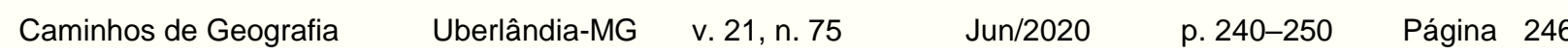


Tabela 4 - Índice de forma (SHAPE_MN) da paisagem do município de Nova Marilândia-MT, nos anos de 1998, 2008 e 2018.

\begin{tabular}{lccc}
\hline \multicolumn{1}{c}{ Classe } & $\mathbf{1 9 9 8}$ & $\mathbf{2 0 0 8}$ & $\mathbf{2 0 1 8}$ \\
\hline Agricultura & 2,26 & 2,74 & 2,29 \\
Formação Savânica & 2,45 & 2,39 & 2,04 \\
Pastagem & 2,48 & 2,38 & 2,35 \\
Usos Antrópicos & 2,61 & 2,50 & 2,53 \\
Vegetação Natural Florestal & 1,45 & 1,40 & 1,41 \\
\hline \multicolumn{4}{c}{ Organização: os autores. }
\end{tabular}

Segundo Forman (1995), a análise da forma dos fragmentos florestais, em relação à sua diversidade e sustentabilidade, é tão relevante quanto ao tamanho, tendo em vista que quanto mais irregulares são fragmentos, mais propensos são a apresentar maior efeito de borda, principalmente os de menor área, em função da maior interação com a matriz (CEMIN et al., 2009).

A relação das formas geométricas dos fragmentos florestais tem influência direta na modificação das características físicas no ambiente. Estas modificações, resultantes dos efeitos de borda, provocam alterações microclimáticas em virtude do aumento de incidência de luz solar e interação de ventos no interior dos fragmentos, refletindo em alterações na amplitude térmica refletindo e, por consequência, na redução da umidade (PIROVANI et al., 2014).

Esse processo influencia na interação entre espécies vegetais e/ou animais provocando efeitos danosos à biodiversidade, a exemplo de aumento da mortalidade de seres adaptados a ambientes escuros e de alta umidade, a redução do processo de decomposição, dificuldade de germinação de sementes e na suscetibilidade a queimadas, afetando principalmente na microbiota, que é mais sensível a intempéries, e espécies endêmicas (GONÇALVES et al., 2019; ANTONELI, OLIVEIRA, BEDNARZ, 2019). Isso resulta em uma perda líquida de espécies vegetais e animas nas áreas de borda (SKOLE e TUKER, 1993).

Diante desse cenário, Tambosi (2014, p. 34) explica que:

"[...] uma das formas de diminuir os efeitos da fragmentação é aumentar a conectividade da paisagem por meio de ações de restauração, facilitando o fluxo de organismos entre os remanescentes, aumentando assim a disponibilidade de recursos e a manutenção dos processos ecológicos."

Nesse processo, cada área necessita receber um tratamento específico, considerando suas particularidades, bem como os atores sociais que ocupam a área degradada e seu entorno, incluindo seus valores e interesses, assim como a atividade econômica desenvolvida (RAMOS et al., 2018), estabelecendo um plano participativo entre gestores e a população a fim de estabelecer e direcionar ações para promoção do planejamento ambiental e uso sustentável das terras.

\section{CONSIDERAÇÕES FINAIS}

Apesar da paisagem do município de Nova Marilândia possuir alta conectividade, houve aumento da complexidade das formas, das distâncias entre os fragmentos de vegetação nativa e redução da conectividade funcional ocasionada pelo aumento expressivo das áreas de Agricultura e Pastagem, principal atividade econômica municipal.

A compreensão da estrutura da paisagem, viabilizada via geotecnologias, é imprescindível para o entendimento das relações ecológicas, favorecendo o monitoramento, os planos de delimitação e de restauração florestal de áreas prioritárias.

Aconselha-se o estabelecimento e/ou ampliação de práticas de cunho conservacionistas, com intuito de contribuir para o aumento da produtividade das áreas que estão em uso, associada à redução de abertura de novas áreas, evitando a desconexão das matrizes florestais remanescentes, visando minimizar os impactos à biodiversidade. 


\section{AGRADECIMENTOS}

O presente trabalho foi realizado com apoio da Coordenação de Aperfeiçoamento de Pessoal de Nível Superior - Brasil (CAPES) - Código de Financiamento 001.

\section{REFERÊNCIAS}

ABDALLA L. S.; CRUZ C. B. M. Análise de fragmentação florestal no município de Silva Jardim, Apa do Rio São João, RJ. Revista Brasileira de Cartografia, v. 67, n. 1, p. 169-184, 2015.

ANTONELI, V.; OLIVEIRA, T.; BEDNARZ, J. A. A fragmentação da floresta é um indicador de compactação do solo em Sistema Faxinal? Caminhos de Geografia, v. 20, n. 72, p. 94-106, 2019. https://doi.org/10.14393/RCG207242140

BATISTELLA, M.; ANDRADE, R. G.; BOLFE, E. L.; VICTORIA, D. C.; SILVA, G. B. S. Geotecnologias e gestão territorial da bovinocultura no Brasil. Revista Brasileira de Zootecnia, v. 40, n. Esp., p. 251-260, 2011.

BERTRAND, G. Paysage et géographie physique globale: esquisse méthodologique. Revue géographique des Pyrénées et du Sud-Ouest, v. 39, n. 3, p. 249-272, 1968. https://doi.org/10.3406/rgpso.1968.4553

BRASIL. Instituto Brasileiro de Geografia e Estatística. Censo Demográfico - 2010. 2012. Disponível em: $<$ https://cidades.ibge.gov.br/brasi//mt/nova-marilandia/panorama>. Acesso em: 06 de agosto de 2018.

CAMPOS, S. A. C.; BACHA, C. J. C. Evolução da agropecuária em São Paulo e Mato Grosso de 1995 a 2006. Teoria e Evidência Econômica, v. 22, n. 46, p. 9-36, 2016. https://doi.org/10.5335/rtee.v22i46.6751

CEMIN, G.; PERICO, E.; REMPEL, C. Composição e configuração da paisagem da sub-bacia do Arroio Jacaré, Vale do Taquari, RS, com ênfase nas áreas de florestas. Revista Árvore, v. 33, n. 4, p. 705-711, 2009. https://doi.org/10.1590/S0100-67622009000400013

CUBA, N. Research note: Sankey diagrams for visualizing land cover dynamics. Landscape and Urban Planning, v. 139, n. 1, p. 163-167, 2015. https://doi.org/10.1016/.landurbplan.2015.03.010

FAHRIG, L. Effects of habitat fragmentation on biodiversity. Annual review of ecology, evolution and systematics, v. 34, n. 1, p. 487-515, 2003. https://doi.org/10.1146/annurev.ecolsys.34.011802.132419

FAHRIG, L.; ARROYO-RODRÍGUEZ, V.; BENNETT, J. R.; BOUCHER-LALONDE, V.; CAZETTA, E.; CURRIE, D. J.; EIGENBROD, F.; FORD, A. T.; HARRISON, S. P.; JAEGER, J. A. G.; KOPER, N.; MARTIN, A. E.; MARTIN, J. L.; METZGER, J. P.; MORRISON, P.; RHODES, J. R.; SAUNDERS, D. A.; SIMBERLOFF, D.; SMITH, A. C.; TISCHENDORF, L.; VELLEND, M.; WATLING, J. I. Is habitat fragmentation bad for biodiversity? Biological Conservation, v. 230, n. 1, p. 179-186, 2019. https://doi.org/10.1016/j.biocon.2018.12.026

FORERO-MEDINA, G.; VIEIRA, M. V. Conectividade funcional e a importância da interação organismopaisagem. Oecologia Brasiliensis, v. 11, n. 4, p. 493-502, 2007. https://doi.org/10.4257/oeco.2007.1104.03

FORMAN, T. T. R. Land mosaics: the ecology of landscapes and regions. Cambridge/UK: Cambridge University Press, 1995. 656 p. https://doi.org/10.1017/9781107050327

GONÇALVES, A. L.; CRUZ, V. M. S.; SERRA, A. B. Fragmentação florestal na Região de Integração do Lago de Tucuruí, Pará, Brasil. Ciências Agrárias/Amazonian Journal of Agricultural and Environmental Sciences, v. 62, n. 1, p. 1-10, 2019. https://doi.org/10.22491/rca.2019.3048

IBGE. Instituto Brasileiro de Geografia e Estatística. Manual Técnico de Geomorfologia. Rio de Janeiro: IBGE, 2009. $182 \mathrm{p}$.

Manual Técnico de Uso da Terra. Rio de Janeiro: IBGE, 2013. 171 p.

Censo Agropecuário. Disponível em: <https://censos.ibge.gov.br/agro/2017/resultados-censoagro-2017.html . Acesso em: 12 de setembro de 2019. 
MATO GROSSO (ESTADO). Secretaria de Estado de Planejamento e Coordenação Geral - SEPLAN. Plano de Longo Prazo de Mato Grosso: Macro-objetivos, metas globais, eixos estratégicos, estratégias e linhas estruturantes. Cuiabá: Central de Texto, 2017. 108 p.

DSEE: Diagnóstico Socioeconômico-Ecológico. Cuiabá: SEPLAN, 2002. Disponível em: <http://www.dados.mt.gov.br/publicacoes/dsee/pedologia/pedologia/rt/DSEE-PD-RT-004-A001.pdf>. Acesso em: 10 de agosto 2019.

Sistema de Informações Cartográficas da SEPLAN-MT (Base Cartográfica). Disponível em: <http://www.seplan.mt.gov.br/-/10951338-bases-cartograficas?ciclo=cv_gestao_inf>. Acesso em: 15 de novembro de 2018.

MCGARIGAL, K.; MARKS, B. J. Fragstats: spatial patterns analysis program for quantifying landscape structure. Portland/USA: USDA, Forest Service, Pacific Northwest Research Station, 1995. 122 p. https://doi.org/10.2737/PNW-GTR-351

METZGER, J. P. Como lidar com regras pouco óbvias para conservação da biodiversidade em paisagens fragmentadas. Natureza \& Conservação, v. 4, n. 2, p. 11-23, 2006.

METZGER, J. P.; ESLER, K.; KRUG, C.; ARIAS, M.; TAMBOSI, L.; CROUZEILLES, R.; ACOSTA, A. L.; BRANCALION, P. H.; D'ALBERTAS, F.; DUARTE, G. T.; GARCIA, L. C.; GRYTNES, J. A.; HAGEN, D.; JARDIM, A. V. F.; KAMIYAMA, C.; LATAWIEC, A. E.; RODRIGUES, R. R.; RUGGIERO, P. G.; SPAROVEK, G.; STRASSBURG, B.; SARAIVA, A. M.; JOLY, C. Best practice for the use of scenarios for restoration planning. Current Opinion in Environmental Sustainability, v. 29, n. 1., p. 14-25, 2017. https://doi.org/10.1016/j.cosust.2017.10.004

NEVES, L. F. S.; NEVES, S. M. A. S.; CANALE, G. R. Análise da fragmentação de cerrado na bacia hidrográfica do rio Aguapeí, Porto Esperidião (MT): um estudo de caso a partir das geotecnologias e métricas da paisagem. Ateliê Geográfico, v. 8, n. 2, p. 130-149, 2014. https://doi.org/10.5216/ag.v8i2.21557

OLIVEIRA, O. A.; TEIXEIRA, T. M. A.; PASSO, D. P. Mapeamento dos conflitos de uso da terra em áreas de preservação permanente dos rios que contribuem para o barramento do rio Paranã. Formosa-GO. Boletim Goiano de Geografia, v. 38, n. 3, p. 491-515, 2018. https://doi.org/10.5216/bgg.v38i3.56348

PAULA, L. F.; PIRES, M. Crise e perspectivas para a economia brasileira. Estudos Avançados, v. 31, n. 89, p. 125-144, 2017. https://doi.org/10.1590/s0103-40142017.31890013

PESSOA, S. P. M.; GALVANIN, E. A. S.; KREITLOW, J. P.; NEVES, S. M. A. S.; NUNES, J. R. S.; ZAGO, B. W. Análise espaço-temporal da cobertura vegetal e uso da terra na interbacia do rio Paraguai MédioMT, Brasil. Revista Árvore, v. 37, n. 1, p. 119-128, 2013. https://doi.org/10.1590/S0100$\underline{67622013000100013}$

PIROVANI, D. B.; SILVA, A. G.; SANTOS, A. R.; CECÍLIO, R. A.; GLERIANI, J. M.; MARTINS, S. V. Análise espacial de fragmentos florestais na Bacia do Rio Itapemirim, ES. Revista Árvore, v. 38, n. 2, p. 271-281, 2014. https://doi.org/10.1590/S0100-67622014000200007

RAMOS, A. W. P.; LUZ, C. C. S.; NEVES, S. M. A. S.; FREITAS, L. E.; NEVES, L. F. S. Análise da capacidade e conflito de uso da terra na bacia hidrográfica do Córrego da Piraputanga-MT, Brasil. Caderno de Geografia, v. 28, n. 55, p. 812-827, 2018. https://doi.org/10.5752/P.23182962.2018v28n55p812-827

RIBEIRO, M. C.; METZGER, J. P.; MARTENSEN, A. C.; PONZONI, F. J. The Brazilian Atlantic Forest: how much is left, and how is the remaining forest distributed? Implications for conservation. Biological Conservation, v. 142, n. 6, p. 1141-1153, 2009. https://doi.org/10.1016/j.biocon.2009.02.021

SANTOS, A. G. Método para georreferenciamento de mapas urbanos baseado na atribuição de pesos aos pontos de controle. 2009. 206 f. Tese (Doutorado em Ciências - Engenharia de Transportes) - Universidade de São Paulo, São Carlos/SP: USP, 2009.

SCHIMIDT, M. The Sankey diagram in energy and material flow management: Part I: History. Journal of Industrial Ecology, v. 12, n. 1, p. 82-94, 2008. https://doi.org/10.1111/j.1530-9290.2008.00004.x

SILVA, S. C. S.; LIMA, A. M. M. Análise do uso e ocupação da terra e sua influência na sub-bacia do JiParaná. Revista Brasileira de Geografia Física, v. 12, n. 1, p. 201-212, 2019. https://doi.org/10.26848/rbgf.v12.1.p201-212 
SKOLE, D.; TUCKER, C. Tropical deforestation and habitat fragmentation in the Amazon: satellite data from 1978 to 1988. Science, v. 260, n. 5116, p. 1905-1910, 1993. https://doi.org/10.1126/science.260.5116.1905

SOUZA, C. G.; ZANELLA, L.; BORÉM, R. A. T.; CARVALHO, L. M. T.; ALVES, H. M. R.; VOLPATO, M. M. L. Análise da fragmentação florestal da área de proteção ambiental Coqueiral, Coqueiral - MG. Ciência Florestal, v. 24, n. 3, p. 631-644, 2014. https://doi.org/10.5902/1980509815743

SU, S. L., XIAO, R., JIANG, Z. L., ZHANG, Y. Characterizing landscape pattern and ecosystem service value changes for urbanization impacts at an eco-regional scale. Applied Geography, v. 34, n. 1, p. 295305, 2012. https://doi.org/10.1016/i.apgeog.2011.12.001

SZMUCHROWSKI, M. A.; MARTINS, I. C. M. M. Geoprocessamento para a Indicação de corredores ecológicos interligando os fragmentos de florestais e áreas de proteção ambiental no Município de Palmas - TO. In: SIMPÓSIO BRASILEIRO DE SENSORIAMENTO REMOTO, 10., 2001, Foz do lguaçu/PR. Anais eletrônicos [...] São José dos Campos/SP: INPE, 2001. p. 675-681. Disponível em: <http://marte.sid.inpe.br/col/dpi.inpe.br/lise/2001/09.19.09.42/doc/0675.681.115.pdf>. Acesso em: 27 de agosto de 2019.

TAMBOSI, L. R. Estratégias espaciais baseadas em ecologia de paisagens para a otimização dos esforços de restauração. 2012. 116 f. Tese (Doutorado em Ecologia) - Universidade de São Paulo, São Paulo, 2014.

TARIFA, J. R. Mato Grosso: Clima - Análise e representação cartográfica. Cuiabá: Entrelinhas, 2011. 102 p.

USGS. United States Geological Survey. Portal de Catálogo de Dados Científicos. 2016. Disponível em: $<$ https://earthexplorer.usgs.gov/>. Acesso em: 08 de outubro de 2018.

XAUD, M. R.; EPIPHANIO, J. C. N. Dinâmica do uso e cobertura da terra no sudeste de Roraima utilizando técnicas de detecção de mudanças. Acta Amazônica, v. 44, n.1, p. 107-120, 2014. https://doi.org/10.1590/S0044-59672014000100011

Recebido em: 19/11/2019

Aceito para publicação em: 20/03/2020 